The Health Impacts of Toxic Remnants of War on Civilian Populations: A Scoping Review

Dr. Jo Durbam ${ }^{1}$, Ms. Stacey Pizzino ${ }^{2}$

1. Queensland University of Technology, Brisbane, Australia

2. University of Queensland, Brisbane, Australia

Introduction: An estimated two billion people are currently affected by war, with civilian populations increasingly exposed to the hazards of armed conflict. While the effect of explosive remnants of conflict is well documented, the impacts of the toxic remnants of war on civilian health are less well understood.

Methods: This study was a scoping review examining the human health impacts of exposure to toxic remnants of war. Toxic remnants of war refer to any toxic or radiological substances arising from military activities. In this study, however, the focus was limited to the health effects of exposure to toxic substances and explosive by-products from munitions fired, dropped, or abandoned during conflict. The following databases were searched: Embase PubMed, Scopus, and Web of Science. The Mixed Methods Appraisal Tool (MMAT) was used to assess the methodological quality of studies that met the inclusion criteria.

Results: Common toxicants reported on were Tetrachlorodibenzo-p-dioxin TCDD, white phosphorus, depleted uranium, lead, mercury, and sulfur mustard. Common health effects included respiratory diseases as well as cutaneous, cardiovascular, reproductive, and congenital effects. Posttraumatic stress disorder, depression, anxiety, cognitive impairments, and decreased quality of life were also commonly reported. The evidence base, however, is mixed with heterogeneity in study design and outcome measures. Lack of baseline data and inadequate exposure models make establishing an adverse causal relationship between an agent and a disease challenging. Discussion: Civilian exposures to toxic remnants of conflict remain understudied and under-addressed. The study suggests assessment of the human health impacts of toxicants should be part of a post-conflict response, especially given the potential long-term intergenerational effects. The current lack of recognition of the human health impacts of toxic remnants of conflict also limits the amount of global resources assigned to postconflict decontamination.

Prehosp. Disaster Med. 2019;34(Suppl. 1):s32

doi:10.1017/S1049023X19000815

International Humanitarian Law and Review of Recurrent Violations Including Chemical Weapons Use

Dr. Sukbshant Atti ${ }^{1}$, Dr. Bonnie Arquilla ${ }^{2}$

1. Emory University, Atlanta, United States

2. SUNY Downstate University, Brooklyn, United States

Introduction: The basis of International Humanitarian Law (IHL) is the Theory of Natural Law, which states that the laws of morality and the ability to use reason in the determination of inalienable human rights, are innate to humans, and cannot be taken away by any states or laws. IHL is an agreement among nation-states that applies to situations of conflict to protect civilians and guides conduct in time of war. IHL extends protection to civilian medical personnel. The recent escalation in chemical weapons use by states has violated IHL and the 1997 Chemical Weapons Convention (CWC) treaty, with little repercussion from the international community.

Aim: We review the increase in chemical weapons use, international chemical weapon treaty violations, and violations of IHL against medical personnel.

Methods: A review was conducted of existing medical and grey literature for sources discussing chemical agents, their history, and violations of laws prohibiting their production, stockpiling, or use. The following publications were reviewed: PubMed, EBSCHost, and Google Scholar.

Results: The use of sarin, chlorine, and mustard gas against civilians has been confirmed multiple times in Syria by the United Nations since 2011. Physicians for Human Rights mapped 537 attacks, both violent and chemical, against 348 different medical facilities in Syria from March 2011 to July 2018. Since March 2011, at least 847 civilian medical personnel have reportedly been killed. Many were killed by government forces as part of a war strategy creating further incapacitation. Most recently, Medecins Sans Frontiers concluded its Yemen mission due to repeated attacks, including two in one week in October 2018.

Discussion: There must be recognition and emphasis on the health severity of such attacks and the violations of IHL and the CWC. Physicians must use their unique positions for advocacy and call for action in upholding international treaties.

Prehosp. Disaster Med. 2019;34(Suppl. 1):s32

doi:10.1017/S1049023X19000827

\section{Newborn and Child Health Care in Humanitarian Crisis Settings: Piloting of Training Package for Primary Health Care Workers in Rural Nepal \\ Dr. Sumana Bajracharya ${ }^{1}$, Dr. Ashis Shrestha ${ }^{1}$, Dr. Rose House ${ }^{2}$ \\ 1. Patan Academy of Health Sciences, Lalitpur, Nepal \\ 2. Indiana University, Indianapolis, United States}

Introduction: The community-based integrated management of newborn and childhood illness (CBIMNCI) training package has been widely used throughout Nepal. Adding a component of disaster response and management to this program would greatly impact the community, and could improve the knowledge and skills of community workers for the management of children during a disaster.

Aim: Describe the development and implementation of a community-based training for children in disasters.

Methods: Using expertise from emergency and pediatric emergency physicians, pediatricians, and psychiatrists, we developed a two-day training and facilitator manual covering topics such as trauma, resuscitation, burn, drowning, disaster, nutrition, and care of the newborn. The information and manuals were presented to the Nepal Division of Child Health for approval. Four pilot trainings were conducted in Bardia and Bardibas in Nepal in September 2017, including knowledge and skillbased sessions. Knowledge was tested pre- and post-training using multiple choice questions (MCQ) and self-reflections. Skills were evaluated by direct observation and marked using 
a Likert scale. Confidence was assessed using a confidence matrix before and after the course. Overall feedback was taken at the end of the session.

Results: Of 82 participants, 74 participants from four trainings were included for analysis. Post-test Cronbach's alpha for MCQ was 0.82 and the confidence matrix was 0.86 . Mean score for the pre-test MCQ was 6.12 (SD 2.22) compared to the post-test mean of 10.97 (SD 2.97), which was a statistically significant improvement $(\mathrm{p}<0.05)$. Trainees reported that the trauma teaching was helpful. They felt that it improved confidence regarding trauma and disasters.

Discussion: Adding this training to current CBIMNCI can be an effective tool to reach out to primary health care workers, and provide further knowledge and skills on care of children during a disaster or humanitarian crisis.

Prehosp. Disaster Med. 2019;34(Suppl. 1):s32-s33

doi:10.1017/S1049023X19000839

Towards a Better Response: Combining Pareto Ranking and Geostatistics to Model Gender-Based Vulnerability in Rohingya Refugee Settlements in Bangladesh

Dr. Erica Nelson ${ }^{1,2}$, Ms. Daniela Reyes Saade ${ }^{3}$,

Dr. P. Gregg Greenough1'2

1. Department of Emergency Medicine, Harvard School of Medicine, Boston, USA

2. Harvard Humanitarian Initiative, Cambridge, USA

3. Clark University, Worcester, USA

Introduction: The Rohingya refugee crisis in Bangladesh continues to overburden humanitarian resources and undermine the health and security of over 900,000 people. Spatial, sector-specific information is required to better understand the needs of vulnerable populations, such as women and girls, and to target interventions with improved efficiency and effectiveness.

Aim: The aim of this study was to create a gender-based vulnerability index and explore the geospatial and thematic variations in the gender-based vulnerability of Rohingya refugees residing in Bangladesh by utilizing pre-existing, open-source data.

Methods: Data sources included remotely-sensed REACH data on humanitarian infrastructure, UN Population Fund resource availability data, and the Needs and Population Monitoring Survey conducted by the International Organization for Migration in October 2017. Gaps in data were addressed through probabilistic interpolation. A vulnerability index was designed through a process of literature review, variable selection and thematic grouping, normalization, and scorecard creation. Pareto ranking was employed to rank sites based on vulnerability scoring. Spatial autocorrelation of vulnerability was analyzed with the Global and Anselin Local Moran's I applied to both combined vulnerability index rank and disaggregated thematic ranking.

Results: Twenty-four percent of settlements were ranked as most vulnerable, with 30 highly vulnerable clusters identified predominantly in the Upazila of Sadar. Five settlements in Dhokkin, Somitipara, and Pahartoli were categorized as less vulnerable outliers amongst highly vulnerable neighboring sites.
Security- and health-related variables appear to be the largest drivers of gender-specific vulnerability in Cox's Bazar. Clusters of low security and education vulnerability measures are shown near the refugee ingress point near Gundum.

Discussion: The humanitarian space produces tremendous amounts of data that can be analyzed with spatial statistics to better target research and programmatic intervention. The critical utilization of these data and validation of vulnerability indexes is required to improve the international response to the global refugee crisis.

Prehosp. Disaster Med. 2019;34(Suppl. 1):s33

doi:10.1017/S1049023X19000840

\section{The Use of Evidence in Humanitarian Response Decision-Making \\ Ms. Dell Saulnier', Claire Allen ${ }^{2}$, Anneli Eriksson ${ }^{1}$, Ben Heaven Taylor ${ }^{2}$ \\ 1. Karolinska Institutet, Stockholm, Sweden \\ 2. Evidence Aid, United Kingdom}

Introduction: The need to use evidence in humanitarian settings is recognized, yet utilizing that evidence to make decisions about humanitarian response remains a challenge.

Aim: To identify how, when, and why decision makers in humanitarian response use scientific, peer-reviewed evidence to make decisions.

Methods: An online cross-sectional survey of fifteen open- and closed-ended questions on demographics, experience, and role in humanitarian response was developed by Evidence Aid (EA) and Karolinska Institutet (KI). The online survey was available on the EA website from August 2015 to October 2018. Participants were self-selected, recruited through social media channels and mailing lists of EA and KI. All respondents and responses were anonymized. Responses were analyzed with descriptive statistics and content analysis.

Results: 47 people responded, primarily working in Europe or North America with roles of humanitarian response director/ manager, independent consultant, or policymaker. Personal assessment of the quality of information, trust in the source, and information that was contextually relevant or based on field experience were factors for deciding whether information should be considered evidence. Reasons for using evidence when making decisions included adhering to good practice to maximize impact and effectiveness of aid, reassurance that the right decisions were being made, personal or organizational values, and using evidence as a tool to protect beneficiaries and organizations from poor quality decisions and program content.

Discussion: Using evidence for decision making was common practice during the process of designing implementing and evaluating humanitarian response content, yet reasons for use varied. The importance of evidence developed and validated from field experience and trust in the source reported by this sample suggests that strengthening collaborative efforts between decisionmakers and evidence generators could be one approach to improve evidence and evidence use in humanitarian response.

Prehosp. Disaster Med. 2019;34(Suppl. 1):s33

doi:10.1017/S1049023X19000852 